Rev. Bras. Saúde Prod. Anim., Salvador, v.13, n.1, p.224-236 jan/mar, 2012 http://www.rbspa.ufba.br ISSN 15199940

\title{
Comportamento ingestivo de novilhas leiteiras alimentadas com níveis de farelo de cacau (Theobroma cacao) na $\operatorname{dieta}^{1}$
}

\author{
Ingestive behavior of dairy heifers fed cocoa ("Theobroma cacao") meal levels in the diet
}

\author{
PINHEIRO, Alyson Andrade ${ }^{2 *}$; VELOSO, Cristina Mattos ${ }^{3}$; ROCHA NETO, Aires \\ Lima $^{4}$; SILVA, Robério Rodrigues ${ }^{5}$; SILVA, Fabiano Ferreira da ${ }^{5}$; MENDES, \\ Fabrício Bacelar Lima ; SANTANA JÚNIOR, Hermógenes Almeida de ${ }^{5}$; \\ AZEVEDO, Saulo Tanus ${ }^{5}$; CARVALHO, Gleidson Giordano Pinto de ${ }^{6}$
}

\footnotetext{
${ }^{1}$ Parte da dissertação do primeiro autor.

${ }^{2}$ Universidade Estadual de Maringá, Departamento de Zootecnia, Maringá, Paraná, Brasil.

${ }^{3}$ Universidade Federal de Viçosa, Departamento de Zootecnia, Viçosa, Minas Gerais, Brasil.

${ }^{4}$ Instituto Federal Baiano, Departamento de Ciências Agrárias, Santa Inês, Bahia, Brasil.

${ }^{5}$ Universidade Estadual do Sudoeste da Bahia, Departamento de Zootecnia, Itapetinga, Bahia, Brasil.

${ }^{6}$ Universidade Federal da Bahia, Departamento de Zootecnia, Salvador, Bahia, Brasil.

*Endereço para correspondência: jagualyson@bol.com.br
}

\section{RESUMO}

Objetivou-se avaliar o comportamento ingestivo de novilhas leiteiras alimentadas com níveis de farelo de cacau $(0 ; 7 ; 14$ e $21 \%)$. Foram utilizadas 20 novilhas leiteiras $3 / 4$ Gir x $1 / 4$ Holandês, com peso corporal inicial médio de $165,5 \pm 35,8 \mathrm{~kg}$. Os animais foram distribuídos em delineamento inteiramente casualizado, com quatro tratamentos e cinco repetições, e receberam dietas compostas de silagem de capim elefante como volumoso e concentrado com níveis crescentes de inclusão de farelo de cacau. Foram avaliados os consumos, assim como suas eficiências de alimentação e ruminação. Para determinação do comportamento ingestivo, as novilhas foram submetidas, no penúltimo dia do período experimental, à observação visual, a cada cinco minutos, durante 24 horas. Os consumos de matéria seca, de fibra em detergente neutro, de carboidratos não fibrosos e de nutrientes digestíveis totais não foram influenciados pelos níveis de inclusão de farelo de cacau na dieta. Os tempos gastos em alimentação, ruminação e ócio não diferiram entre os tratamentos, assim como o número de períodos e os tempos gastos em cada período das respectivas atividades. $\mathrm{O}$ tempo gasto por bolo ruminado, o número de mastigações por bolo, o número de bolos ruminados por dia e o tempo de mastigação total não sofreram efeito das dietas. A eficiência de alimentação dos carboidratos não fibrosos teve efeito linear crescente, à medida que foi incluso o farelo de cacau na dieta. A inclusão de até $21 \%$ de farelo de cacau na dieta total não altera o comportamento ingestivo de novilhas leiteiras.

Palavras chave: alimentação, bovino, etologia, resíduo, ruminação

\section{SUMMARY}

The objective was to evaluate the ingestive behavior of dairy heifers fed different cocoa meal levels. Twenty $3 / 4$ Gir x $1 / 4$ Holstein dairy heifers, with $165.5 \pm 35.8 \mathrm{~kg}$ of body weight, were used. The animals were distributed in a completely randomized design, with four treatments and five repetitions, receiving diets composed by elephant grass silage as the roughage and concentrate with increasing levels of cocoa meal. The intakes were evaluated, and also their feeding and rumination efficiencies. To determine the ingestive behavior, the heifers were submitted, in the last day of the experimental period, to visual observation, at each five minutes, during 24 hours. The dry matter, neutral detergent fiber, non- fiber carbohydrates and total digestible nutrients intakes were not influenced by cocoa meal inclusion levels in the diet. The time spent feeding, ruminating and in idle did not differ among treatments, neither did the number of periods and the time spent in each period with the respective 
activities. The time per ruminated bolus, chewing number per bolus, number of ruminated bolus per day and total chewing time were not affected by the diets. The non-fiber carbohydrates feeding efficiency had increasing linear effect as cocoa meal was included in the diet. The inclusion of up to $21 \%$ of cocoa meal in the total diet did not alter negatively the ingestive behavior of dairy heifers.

Keywords: bovine, ethology, food, rumination, waste

\section{INTRODUÇÃO}

No Brasil, os ganhos de peso dos animais são normalmente moderados, o que implica em aumento no período de recria. Desta forma, o pecuarista torna-se compelido a buscar alimentos alternativos que minimizem os custos com a alimentação animal e possam gerar economicidade ao sistema produtivo como um todo.

Os ruminantes possuem elevada capacidade de utilização de resíduos e coprodutos agroindustriais, os quais são utilizados muitas vezes sem mesmo serem conhecidos seus aspectos na nutrição animal.

O farelo de cacau (Theobroma cacao) é um resíduo da retirada do tegumento, antes da torrefação das sementes de cacau para produção da manteiga ou chocolate (COMPÊNDIO BRASILEIRO DE ALIMENTAÇÃO ANIMAL, 2002). É encontrado em abundância no estado da Bahia com preços bastante acessíveis. Por ser um alimento não convencional é importante conhecer o comportamento ingestivo dos animais, de modo a proporcionar maior entendimento da aceitação, ingestão e eficiência de consumo dos alimentos pelos animais.

Carvalho et al. (2004, 2006, 2007, 2008) e Pires et al. $(2004,2005)$ avaliaram o comportamento ingestivo de animais alimentados com farelo de cacau para descobrir o potencial de sua utilização na alimentação de ruminantes. Nas recomendações gerais desses estudos, foi sugeridas adição de 12,15 e $18 \%$ de farelo de cacau na dieta total de ovinos, bovinos e caprinos.

Objetivou-se avaliar o comportamento ingestivo de novilhas leiteiras alimentadas com níveis de farelo de cacau nas porções de $0 ; 7 ; 14$ e 21\%.

\section{MATERIAL E MÉTODOS}

O experimento foi conduzido no Laboratório Experimental de Bovinos do Setor de Bovinocultura de Leite do campus da Universidade Estadual do Sudoeste da Bahia - UESB.

Foram utilizadas 20 novilhas mestiças Holandesas x Zebus (grau de sangue $3 / 4$ Gir x $1 / 4$ Holandês), com peso corporal médio inicial de 165,5 \pm $35,8 \mathrm{~kg}$ e idade média de $13 \pm 3$ meses, confinadas em baias individuais com $2,5 \mathrm{~m}^{2}$ de área útil e piso de concreto, providas de comedouro de concreto e bebedouros automáticos. Os animais passaram por um período de 16 dias de adaptação, e todos foram identificados com número e tratados contra ecto e endoparasitas. $\mathrm{O}$ experimento teve duração de 84 dias.

As novilhas foram pesadas e distribuídas em quatro tratamentos, compostos por quatro diferentes níveis de inclusão de farelo de cacau (FC) na matéria seca (MS) das dietas nas porções de $0 ; 7 ; 14$ e 21\%, em delineamento inteiramente casualizado, com cinco repetições.

$\mathrm{O}$ volumoso utilizado foi silagem de capim-elefante cortado aos 100 dias. As dietas foram formuladas para suprir as exigências para ganho diário de $600 \mathrm{~g}$, de acordo com o NRC (2001), com base nos dados da análise bromatológica da silagem de capim- 
Rev. Bras. Saúde Prod. Anim., Salvador, v.13, n.1, p.224-236 jan/mar, 2012 http://www.rbspa.ufba.br ISSN 15199940

elefante, previamente preparada no início do período de adaptação.

$\mathrm{O}$ teor de nutrientes digestíveis totais (NDT) da silagem e dos concentrados foi estimado a partir da equação de regressão NDT $=74,49-0,5635^{*}$ FDA $\left(\mathrm{R}^{2}=0,84\right)$, descrita por Cappelle et al. (2001) para volumosos e, para concentrados, NDT $=60,04-0,6083 *$ FDA. As dietas foram calculadas na tentativa de serem isoproteicas e isoenergéticas.
Para calcular as proporções estimadas dos ingredientes nos concentrados, com base na MS conforme a Tabela 1, foi considerada relação volumoso:concentrado de 63,10:36,90; $60,87: 39,13 ; 58,70: 41,30$ e 53,28:46,72, com base na MS, para as dietas contendo $0 ; 7 ; 14$ e $21 \%$ de farelo de cacau.

Tabela 1. Proporção percentual dos ingredientes nos concentrados, com base na matéria seca

\begin{tabular}{|c|c|c|c|c|}
\hline \multirow{3}{*}{ Ingredientes } & \multicolumn{4}{|c|}{ Concentrados } \\
\hline & \multicolumn{4}{|c|}{ Nível de farelo de cacau na MS da dieta (\%) } \\
\hline & 0 & 7 & 14 & 21 \\
\hline Farelo de cacau & 0,00 & 18,11 & 34,21 & 45,31 \\
\hline Milho grão moído & 62,53 & 41,73 & 33,04 & 33,60 \\
\hline Farelo de soja & 29,43 & 34,54 & 28,82 & 15,65 \\
\hline Fosfato bicálcico & 3,06 & 2,43 & 1,92 & 1,79 \\
\hline Calcário calcítico & 0,95 & 0,84 & 0,00 & 0,50 \\
\hline Sal mineral $^{1}$ & 1,39 & 1,31 & 1,23 & 1,09 \\
\hline Ureia & 2,64 & 1,05 & 0,78 & 2,08 \\
\hline
\end{tabular}

${ }^{1}$ Composição: Cálcio $=17,9 \%$; Fósforo $=8,8 \%$; Magnésio $=0,5 \%$; Enxofre $=1,2 \%$; Sódio $=10,3 \%$;

Selênio $=18 \mathrm{ppm} ;$ Cobre $=1550 \mathrm{ppm} ;$ Zinco $=4500 \mathrm{ppm} ;$ Manganês $=1400 \mathrm{ppm} ;$ Iodo $=150 \mathrm{ppm} ;$

Cobalto $=107 \mathrm{ppm}$.

A ração foi fornecida duas vezes ao dia, pela manhã, às 07:00h, e à tarde, às 15h:30min, e ajustadas de forma a manter sobras em torno de $5 \%$ do fornecido, com água permanentemente à disposição dos animais. As quantidades de alimentos fornecidos e de sobras foram registradas diariamente. Foram colhidas, diariamente, amostras de silagem e de sobras, por animal, e semanalmente, amostras dos concentrados, por tratamento. As amostras diárias de silagem e de sobras foram agrupadas de forma proporcional em cada período de 14 dias, constituindose uma amostra composta. Todas as amostras foram pré-secas em estufa de ventilação forçada a $55^{\circ} \mathrm{C}$ e moídas em moinho com peneira de malha de $1 \mathrm{~mm}$, para posteriores análises laboratoriais.

As determinações de MS, matéria orgânica (MO), nitrogênio total (NT), extrato etéreo (EE), fibra em detergente neutro (FDN), fibra em detergente ácido (FDA) e matéria mineral (MM) foram realizadas conforme Silva \& Queiroz (2002), e o teor de proteína bruta (PB) calculado ao multiplicar o NT pelo fator 6,25 .

Os teores de carboidratos totais (CT) e carboidratos não-fibrosos (CNF) foram obtidos pelas equações abaixo, conforme recomendações de Sniffen et al. (1992): 
Rev. Bras. Saúde Prod. Anim., Salvador, v.13, n.1, p.224-236 jan/mar, 2012 http://www.rbspa.ufba.br ISSN 15199940

$\mathrm{CT}=100-(\% \mathrm{~PB}+\% \mathrm{EE}+\% \mathrm{MM}) ;$ e $\mathrm{CNF}=100-(\% \mathrm{~PB}+\% \mathrm{EE}+\% \mathrm{MM}+$ $\% \mathrm{FDN}$ ).

A composição químico-bromatológica da silagem de capim-elefante (SCE), do FC e dos concentrados e o NDT da SCE e do FC, na base da MS, encontra-se na Tabela 2.

Na Tabela 3 encontra-se a composição bromatológica das dietas totais fornecidas nos quatro tratamentos.

A observação do comportamento ocorreu no penúltimo dia de cada período de coleta de dados. Os animais foram observados simultaneamente durante 24 horas, em intervalos de cinco minutos, o que totalizou 288 observações diárias (GARY et al., 1970) para identificar o tempo destinado às atividades de alimentação, ruminação e ócio.

Foram realizadas observações por quatro períodos do dia (manhã, tarde, noite e madrugada) para determinar o número de mastigações merícicas/bolo ruminal e o tempo gasto para ruminação de cada bolo.

Tabela 2. Composição bromatológica da silagem de capim-elefante (SCE), do farelo de cacau (FC) e dos concentrados experimentais, com base na matéria seca

\begin{tabular}{|c|c|c|c|c|c|c|}
\hline \multirow{3}{*}{ Variáveis (\%) } & \multirow{3}{*}{ SCE } & \multirow{3}{*}{$\mathrm{FC}$} & \multicolumn{4}{|c|}{ Concentrados } \\
\hline & & & \multicolumn{4}{|c|}{ Nível de farelo de cacau na MS da dieta (\%) } \\
\hline & & & 0 & 7 & 14 & 21 \\
\hline MS & 24,3 & 89,0 & 88,1 & 88,2 & 88,1 & 88,1 \\
\hline MO & 90,6 & 92,2 & 92,3 & 93,0 & 92,3 & 92,2 \\
\hline PB & 4,6 & 16,6 & 30,5 & 29,3 & 26,8 & 27,5 \\
\hline $\mathrm{NIDN}^{1}$ & 21,3 & 51,9 & 14,3 & 24,4 & 26,1 & 29,7 \\
\hline NIDA $^{1}$ & 18,6 & 42,7 & 6,5 & 16,9 & 19,5 & 21,6 \\
\hline $\mathrm{EE}$ & 3,8 & 5,8 & 3,8 & 3,3 & 3,5 & 3,9 \\
\hline $\mathrm{CT}^{2}$ & 82,8 & 77,3 & 58,0 & 58,9 & 62,0 & 60,8 \\
\hline FDN & 82,9 & 58,6 & 30,7 & 37,1 & 42,6 & 44,9 \\
\hline FDNcp & 77,7 & 40,8 & 22,2 & 25,8 & 31,5 & 34,7 \\
\hline FDA & 56,2 & 44,8 & 6,8 & 16,9 & 22,4 & 27,1 \\
\hline $\mathrm{CNF}^{3}$ & 0,8 & 18,8 & 27,3 & 21,8 & 19,4 & 15,9 \\
\hline Hem & 13,4 & 13,8 & 10,9 & 8,9 & 8,9 & 7,6 \\
\hline $\mathrm{Cel}$ & 43,6 & 22,2 & 5,5 & 10,7 & 14,8 & 16,1 \\
\hline Lig & 6,4 & 17,7 & 0,76 & 4,8 & 8,5 & 10,0 \\
\hline MM & 9,4 & 7,8 & 7,7 & 7,0 & 7,7 & 7,8 \\
\hline FDAi & 24,6 & 28,5 & 1,0 & 5,8 & 12,0 & 13,6 \\
\hline NDTest. & 42,8 & 32,8 & - & - & - & - \\
\hline \multicolumn{7}{|c|}{$\begin{array}{l}\text { MS = matéria seca; } \mathrm{MO}=\text { matéria orgânica; } \mathrm{PB}=\text { proteína bruta; NIDN }=\text { nitrogênio insolúvel em } \\
\text { detergente neutro; NIDA = nitrogênio insolúvel em detergente ácido; } \mathrm{EE}=\text { extrato etéreo; } \\
\mathrm{CT}=\text { carboidratos totais; FDN }=\text { fibra em detergente neutro; FDNcp }=\text { fibra em detergente neutro } \\
\text { corrigida para cinza e proteína; FDA = fibra em detergente ácido; } \mathrm{CNF}=\text { carboidratos não fibrosos; } \\
\text { Hem = hemicelulose; Cel = celulose; Lig = lignina; } \mathrm{MM}=\text { matéria mineral; FDAi = fibra em detergente } \\
\text { ácido indigestível; } \mathrm{NDT}=\text { nutrientes digestíveis totais. } \\
{ }^{1} \text { Porcentagem do nitrogênio total; }{ }^{2} \mathrm{CT}=100-(\% \mathrm{~PB}+\% \mathrm{EE}+\% \mathrm{MM})-(\text { Sniffen et al., 1992); } \\
{ }^{3} \mathrm{CNF}=100-(\% \mathrm{~PB}+\% \mathrm{EE}+\% \mathrm{MM}+\% \mathrm{FDN})-(\text { Sniffen et al., } 1992) .\end{array}$} \\
\hline
\end{tabular}


Rev. Bras. Saúde Prod. Anim., Salvador, v.13, n.1, p.224-236 jan/mar, 2012 http://www.rbspa.ufba.br ISSN 15199940

Tabela 3. Composição bromatológica das dietas experimentais fornecidas nos quatro tratamentos, com base na matéria seca

\begin{tabular}{lrrrr}
\hline \multirow{2}{*}{ Variável } & \multicolumn{4}{c}{ Nível de farelo de cacau na MS da dieta (\%) } \\
\cline { 2 - 5 } \cline { 2 - 5 } MS & \multicolumn{1}{c}{7} & 49,3 & 14 & \multicolumn{1}{c}{21} \\
MO & 47,8 & 91,5 & 50,6 & 54,1 \\
PB & 91,2 & 14,3 & 91,3 & 91,3 \\
NIDN $^{1}$ & 14,2 & 22,5 & 13,8 & 15,3 \\
NIDA $^{1}$ & 18,7 & 17,9 & 23,3 & 25,2 \\
EE & 14,1 & 3,6 & 18,9 & 20,0 \\
FDN & 3,8 & 65,0 & 3,7 & 3,8 \\
FDNcp & 63,6 & 57,4 & 66,3 & 65,1 \\
FDA & 57,2 & 40,8 & 58,6 & 57,6 \\
CT & 38,0 & 73,1 & 42,2 & 42,6 \\
CNF & 73,3 & 9,0 & 73,9 & 72,2 \\
Hem & 10,6 & 11,6 & 8,5 & 7,9 \\
Cel & 12,5 & 30,7 & 11,5 & 10,7 \\
Lig & 29,6 & 5,7 & 31,7 & 30,8 \\
MM & 4,3 & 8,5 & 7,2 & 8,1 \\
FDAi & 8,8 & 17,2 & 8,7 & 8,7 \\
NDTest. & 15,9 & 53,7 & 19,4 & 19,5 \\
\hline
\end{tabular}

MS = matéria seca; $\mathrm{MO}=$ matéria orgânica; $\mathrm{PB}=$ proteína bruta; NIDN = nitrogênio insolúvel em detergente neutro; NIDA = nitrogênio insolúvel em detergente ácido; $\mathrm{EE}=$ extrato etéreo; $\mathrm{CT}=$ carboidratos totais; FDN $=$ fibra em detergente neutro; FDNcp $=$ fibra em detergente neutro corrigida para cinza e proteína; FDA = fibra em detergente ácido; $\mathrm{CNF}=$ carboidratos não fibrosos; $\mathrm{Hem}=$ hemicelulose $; \mathrm{Cel}=$ celulose $; \mathrm{Lig}=$ lignina; $\mathrm{MM}=$ matéria mineral; $\mathrm{FDAi}=$ fibra em detergente ácido indigestível; $\mathrm{NDT}=$ nutrientes digestíveis totais.

${ }^{1}$ Porcentagem do nitrogênio total; ${ }^{2} \mathrm{CT}=100-(\% \mathrm{~PB}+\% \mathrm{EE}+\% \mathrm{MM})-($ Sniffen et al., 1992); ${ }^{3} \mathrm{CNF}=100-(\% \mathrm{~PB}+\% \mathrm{EE}+\% \mathrm{MM}+\% \mathrm{FDN})-($ Sniffen et al., 1992).

Para estimar o tempo gasto em cada atividade foram utilizados cronômetros digitais, manuseados por quatro observadores previamente treinados, que observaram os animais nos períodos prédeterminados. No período noturno, o ambiente recebeu iluminação artificial. A coleta de dados referentes aos fatores comportamentais: eficiência de alimentação (EAL) e ruminação (ER), tempo médio gasto por bolo ruminado (TBR), número de mastigações por bolo (NMB), número de bolos ruminados por dia (NBRD) e tempo de mastigação total (TMT), foi conduzida conforme metodologia descrita por Bürger et al. (2000).

Para análise dos resultados, foi utilizado o SAEG - Sistema de Análises Estatísticas e Genéticas (UFV, 2001), interpretados por meio de análises de variância e regressão, a $5 \%$ de probabilidade.

\section{RESULTADOS E DISCUSSÃO}

O consumo de MS não sofreu alteração significativa $(\mathrm{P}>0,05)$ com a inclusão de farelo de cacau (Tabela 4). 
Rev. Bras. Saúde Prod. Anim., Salvador, v.13, n.1, p.224-236 jan/mar, 2012 http://www.rbspa.ufba.br ISSN 15199940

O NRC (2001) recomenda, para novilhas leiteiras em crescimento, um consumo de 4,66kg de MS/dia, bastante parecido com a média encontrada no presente estudo (Tabela 4).

Mesmo com alto teor de fibra em detergente neutro $(58,6 \%)$, apresentado pelo farelo de cacau (FC), o consumo desta fração não sofreu efeito $(\mathrm{P}>0,05)$ dos níveis de inclusão, quando expresso em kg/dia (Tabela 4). Como visto na Tabela 2, os concentrados tinham diferentes níveis de fibra em detergente neutro (FDN), porém, a dieta continha teores similares, quando observada a diferença na relação volumoso:concentrado. $\mathrm{O}$ valor médio de consumo de FDN de 2,9kg/dia, mostrou-se um pouco alto, quando comparado ao citado por Mertens (1987), com $1 \%$ do peso corporal, para novilhas em crescimento. Outro fator que pode ter elevado o consumo de FDN foi a qualidade da silagem de capim-elefante fornecida aos animais, que apresentava alto teor deste constituinte.

Tabela 4. Consumo médio (kg/dia) de MS, FDN, CNF e NDT, em função dos níveis de farelo de cacau na dieta de novilhas

\begin{tabular}{|c|c|c|c|c|c|c|c|}
\hline \multirow{2}{*}{ Variável } & \multicolumn{4}{|c|}{ Nível de farelo de cacau na dieta (\%) } & \multirow{2}{*}{$\mathrm{CV}$} & \multirow{2}{*}{ ER } & \multirow{2}{*}{$\mathrm{R}^{2}$} \\
\hline & 0 & 7 & 14 & 21 & & & \\
\hline CMS (kg/dia) & 4,70 & 4,67 & 4,60 & 4,74 & 25,50 & $\hat{\mathrm{Y}}=4,67$ & - \\
\hline CFDN (kg/dia) & 2,84 & 2,89 & 2,92 & 2,98 & 25,90 & $\hat{\mathrm{Y}}=2,90$ & - \\
\hline CCNF (kg/dia) & 0,59 & 0,50 & 0,47 & 0,44 & 24,10 & $\hat{\mathrm{Y}}=0,50$ & - \\
\hline CNDT (kg/dia) & 2,69 & 2,55 & 2,39 & 2,61 & 27,80 & $\hat{Y}=2,56$ & - \\
\hline
\end{tabular}

Não foi observada diferença significativa $(\mathrm{P}>0,05)$ quanto ao consumo de carboidratos não fibrosos $(\mathrm{CNF})$ e nutrientes digestíveis totais (NDT), cujos valores médios diários foram de $0,5 \mathrm{e}$ $2,56 \mathrm{~kg} / \mathrm{dia}$. O consumo de NDT foi inferior ao recomendado pelo NRC
(2001) para novilhas em crescimento, que é de $2,87 \mathrm{~kg} /$ dia. Uma explicação para esse fato são os altos teores de fibra da silagem e do farelo de cacau, o que pode diminuir o teor de energia da dieta.

Tabela 5. Tempo médio em (minutos) das atividades de alimentação, ruminação e ócio, em função dos níveis de farelo de cacau na dieta de novilhas

\begin{tabular}{|c|c|c|c|c|c|c|c|}
\hline \multirow{2}{*}{ Variável } & \multicolumn{4}{|c|}{ Nível de farelo de cacau na dieta $(\%)$} & \multirow{2}{*}{$\mathrm{CV}$} & \multirow{2}{*}{ ER } & \multirow{2}{*}{$\mathrm{R}^{2}$} \\
\hline & 0 & 7 & 14 & 21 & & & \\
\hline Alimentação & 279 & 275 & 248 & 269 & 14,04 & $\hat{\mathrm{Y}}=268$ & - \\
\hline Ruminação & 421 & 504 & 466 & 477 & 11,09 & $\hat{\mathrm{Y}}=467$ & - \\
\hline Ócio & 740 & 661 & 726 & 694 & 9,92 & $\hat{\mathrm{Y}}=705$ & - \\
\hline
\end{tabular}


A ausência de efeito $(\mathrm{P}>0,05)$ encontrada nas atividades de alimentação, ruminação e ócio acompanhou o consumo de MS, o qual não foi influenciado pela inclusão de farelo de cacau (Tabela 5). Silva et al. (2005); Mendes Neto et al. (2007) e Pereira et al., 2007) trabalharam com diferentes teores de FDN e encontraram diferenças no consumo de alimentos e, consequentemente, nos tempos de alimentação. Teores semelhantes de FDN nas dietas do presente estudo podem explicar a não significância das atividades entre os tratamentos, já que o tempo despendido em alimentação é proporcional ao teor de FDN das dietas (VAN SOEST, 1994).

Os resultados encontrados de tempo médio diário de alimentação, ruminação e ócio foram de 267; 467 e $694 \mathrm{~min} / \mathrm{dia}$, respectivamente. Carvalho et al. (2008), ao utilizarem farelo de cacau na dieta de ovinos, encontraram valores similares para a atividade de ruminação. Porém, para a atividade de alimentação, encontraram valores mais altos e, em consequência disso, valores mais baixos para a atividade de ócio. Já Pereira et al. (2007), ao trabalharem com diferentes grupos genéticos de novilhas leiteiras, alimentadas com diferentes níveis de fibra, encontraram valores inferiores de tempo de alimentação, similares de ruminação e maiores de ócio. O número de períodos e o tempo por período de alimentação, ruminação e ócio não foi afetado $(\mathrm{P}>0,05)$ pela inclusão de farelo de cacau (Tabela 6).

Tabela 6. Número de períodos de alimentação (NPA), ruminação (NPR) e ócio (NPO), tempo médio de duração dos períodos de alimentação (TPA), ruminação (TPR) e ócio (TPO), em função dos níveis de farelo de cacau na dieta de novilhas

\begin{tabular}{|c|c|c|c|c|c|c|c|}
\hline \multirow{2}{*}{ Variável } & \multicolumn{4}{|c|}{ Nível de farelo de cacau na dieta (\%) } & \multirow{2}{*}{$\mathrm{CV}$} & \multirow{2}{*}{ ER } & \multirow{2}{*}{$\mathrm{R}^{2}$} \\
\hline & 0 & 7 & 14 & 21 & & & \\
\hline NPA & 12 & 15 & 12 & 12 & 21,04 & $\hat{\mathrm{Y}}=13$ & - \\
\hline NPR & 24 & 26 & 25 & 24 & 9,55 & $\hat{\mathrm{Y}}=25$ & - \\
\hline NPO & 34 & 36 & 33 & 32 & 9,60 & $\hat{\mathrm{Y}}=34$ & - \\
\hline TPA (min) & 23 & 17 & 20 & 22 & 24,01 & $\hat{\mathrm{Y}}=21$ & - \\
\hline TPR (min) & 17 & 19 & 18 & 19 & 11,79 & $\hat{\mathrm{Y}}=18$ & - \\
\hline TPO (min) & 22 & 18 & 21 & 21 & 15,23 & $\hat{Y}=21$ & - \\
\hline
\end{tabular}

$\mathrm{CV}=$ coeficiente de variação (\%); ER = equação de regressão; $\mathrm{R}^{2}=$ coeficiente de determinação.

Segundo Silva et al. (2005), o padrão de procura de alimentos por bovinos confinados é bem característico, com dois momentos principais: início da manhã e final da tarde. Mendes Neto et al. (2007) relataram que a modificação no horário ou na frequência de fornecimento da dieta ao animal pode modificar a distribuição percentual dos horários de alimentação de animais em confinamento. Por isso, no presente estudo, não foi verificada diferença no número de períodos de alimentação, ruminação e ócio, uma vez que as dietas eram rigorosamente fornecidas no mesmo horário, todos os dias (às $7 \mathrm{hs} \mathrm{e}$ às $15 \mathrm{~h} 30 \mathrm{~min})$. 
Carvalho et al. (2008) relataram que o consumo diário de alimentos pode ser descrito pelo número de refeições consumidas por dia, pela duração e pela taxa de alimentação, a qual é representada pela velocidade em que cada refeição é feita. Explica-se, assim, a diferença encontrada entre os números de períodos de alimentação e os tempos médios de duração dos períodos de alimentação do presente estudo em relação aos relatados por Carvalho (2008), que utilizou, como volumoso, cana-de-açúcar, a qual possui maior teor de fibra de baixa digestão. No presente estudo, os animais tiveram baixo número de períodos de alimentação (NPA), porém, com maior duração por período (TPA). Já os animais do estudo de Carvalho (2008) alimentavam-se por um tempo mais curto, porém, precisavam se alimentar mais vezes para suprir suas exigências. Segundo o autor, à medida que pequenas porções dos alimentos são degradadas e direcionadas aos compartimentos posteriores, ocorre a necessidade de ingestão de mais alimentos, a qual é praticada em pequenas quantidades.

O presente estudo apresentou média de 13 refeições diárias, o que está bem próximo ao determinado por Bürger et al. (2000), que foi de 14 períodos de alimentação por dia, em bezerros. Desta forma, nota-se que, mesmo trabalhando com animais de diferentes categorias, não há grande disparidade nos valores referentes aos números de períodos despendidos nestas atividades. $\mathrm{O}$ número médio de períodos de ruminação encontrado foi de 25 . Em contrapartida, o tempo gasto em cada período ruminativo foi muito maior (40 minutos) do que o verificado no presente estudo (18 minutos). A disparidade entre os valores pode ser atribuída à qualidade do volumoso utilizado pelos autores supracitados.

Não houve efeito $(\mathrm{P}>0,05)$ dos tratamentos sobre tempo médio gasto por bolo ruminado (TBR), número de mastigações por bolo (NMB), número de bolos ruminados por dia (NBRD) e tempo de mastigação total (TMT) - (Tabela 7).

Tabela 7. Tempo médio gasto por bolo ruminado (TBR), em segundos, número de mastigações por bolo (NMB), número de bolos ruminados por dia (NBRD) e tempo de mastigação total (TMT), em função dos níveis de farelo de cacau na dieta de novilhas

\begin{tabular}{|c|c|c|c|c|c|c|c|}
\hline \multirow{2}{*}{ Variável } & \multicolumn{4}{|c|}{ Nível de farelo de cacau na dieta (\%) } & \multirow{2}{*}{$\mathrm{CV}$} & \multirow{2}{*}{ ER } & \multirow{2}{*}{$\mathrm{R}^{2}$} \\
\hline & 0 & 7 & 14 & 21 & & & \\
\hline TBR (s/bolo) & 56 & 54 & 48 & 63 & 19,60 & $\hat{\mathrm{Y}}=55$ & - \\
\hline NMB (nº /bolo) & 58 & 60 & 57 & 71 & 15,90 & $\hat{\mathrm{Y}}=62$ & - \\
\hline NBRD (nº/dia) & 459 & 561 & 594 & 479 & 23,40 & $\hat{\mathrm{Y}}=523$ & - \\
\hline TMT (min) & 700 & 779 & 714 & 746 & 9,50 & $\hat{Y}=735$ & - \\
\hline
\end{tabular}

$\mathrm{CV}=$ coeficiente de variação (\%); ER = equação de regressão; $\mathrm{R}^{2}=$ coeficiente de determinação.

Esses resultados acompanham os encontrados para as atividades de alimentação e ruminação, que também não sofreram efeito da inclusão de farelo de cacau, conforme Tabela 5. No estudo realizado por Mendes Neto et al. 
(2007), foram verificados valores de TBR e NMB similares aos do presente estudo. Os autores também não encontraram diferença significativa para as variáveis, com a inclusão de polpa cítrica em substituição ao feno de capim Tifton 85. Silva et al. (2005), que incluíram diferentes níveis de bagaço de mandioca na dieta de novilhas observaram, para as variáveis TBR e $\mathrm{NMB}$, valores de 46,5s/bolo e 52 mastigações/bolo, respectivamente, os quais se mostraram inferiores aos do presente estudo, que foram de $56 \mathrm{~s} /$ bolo e 62 mastigações/bolo.

$\mathrm{O}$ número de bolos ruminados por dia foi similar ao de Mendes Neto et al. (2007) e Silva et al. (2005). Pereira et al. (2009) trabalharam com bovinos da raça Holandesa, alimentados com dietas que continham feno de capim Tifton 85 com diversos tamanhos de partícula e encontraram média de 632,88 bolos ruminais por dia. Mendes Neto et al. (2007), também utilizaram capim Tifton, e encontraram média de 557,25 bolos ruminais no período de 24 horas. No presente estudo foram verificados 523,72 bolos/dia.

O menor peso da categoria animal trabalhada no presente estudo e nos de Mendes Neto et al. (2007) pode ser a resposta da menor quantidade de bolos encontrados, quando comparados aos de Pereira et al. (2009).

O tempo de mastigação total (TMT) é obtido pela soma do tempo de alimentação e do tempo de ruminação, durante as 24 horas de observação. Diante disso, pode-se justificar a semelhança quanto ao tempo de mastigação total entre os tratamentos, uma vez que não houve diferença entre os tempos de alimentação e ruminação. Pereira et al. (2007) avaliaram o comportamento ingestivo de novilhas leiteiras que recebiam dietas com diferentes níveis de fibra e detectaram maior tempo de mastigação total quando os animais foram submetidos à dieta com teor mais elevado de FDN (60\%). Isso comprova que a qualidade química $\mathrm{e}$ física dos volumosos está diretamente relacionada aos aspectos comportamentais dos ruminantes. Ao se comparar os estudos com cana-de-açúcar na alimentação de ruminantes Mendonça et al. (2004) e Carvalho (2008), é possível verificar uma grande amplitude referente ao tempo de mastigação total, que pode variar de 728,6 a 948,6 min/dia. Uma explicação para tal variação é a diferente composição dos concentrados oferecidos aos animais, os quais podem contribuir positiva ou negativamente para a digestão da dieta.

As eficiências de alimentação expressas em $\mathrm{kg}$ de MS, FDN e NDT por hora, não foram influenciadas $(\mathrm{P}>0,05)$ pela inclusão de farelo de cacau, conforme a Tabela 8. Ao compilar os dados de Silva et al. (2005) e Mendes Neto et al. (2007), que trabalharam com novilhas leiteiras, verifica-se que todos eles encontraram valores inferiores de EAMS e EAFDN. Esse fato pode ser atribuído às características químicas e físicas da composição do farelo de cacau utilizado na dieta do atual estudo. Os valores de EACNF (Figura 1) diferiram significativamente entre os tratamentos $(\mathrm{P}<0,05)$ e apresentaram efeito linear crescente, o que corrobora os resultados encontrados por Silva et al. (2005), que trabalharam com novilhas em confinamento, com quatro níveis de bagaço de mandioca. Mesmo com os valores próximos, os autores não encontraram efeito dos tratamentos. $\mathrm{O}$ aumento linear da EACNF pode estar relacionado com o fato de as dietas apresentarem valores inferiores de CNF à medida que se incluiu farelo de cacau (Tabela 3). 
Rev. Bras. Saúde Prod. Anim., Salvador, v.13, n.1, p.224-236 jan/mar, 2012 http://www.rbspa.ufba.br ISSN 15199940

Tabela 8. Eficiência de alimentação (EA) e de ruminação (ER) de MS, FDN, CNF e NDT, em função dos níveis de farelo de cacau na dieta de novilhas

\begin{tabular}{|c|c|c|c|c|c|c|c|}
\hline \multirow{2}{*}{ Variável } & \multicolumn{4}{|c|}{ Nível de farelo de cacau na dieta (\%) } & \multirow{2}{*}{$\mathrm{CV}$} & \multirow{2}{*}{ ER } & \multirow{2}{*}{$\mathrm{R}^{2}$} \\
\hline & 0 & 7 & 14 & 21 & & & \\
\hline \multicolumn{8}{|c|}{ Eficiência de alimentação } \\
\hline EAMS (kg MS/h) & 2,23 & 2,20 & 2,52 & 3,13 & 18,23 & $\hat{\mathrm{Y}}=2,52$ & - \\
\hline EAFDN (kg FDN/h) & 1,13 & 1,08 & 1,20 & 1,22 & 18,28 & $\hat{\mathrm{Y}}=1,16$ & - \\
\hline EACNF (kg CNF/h) & 0,58 & 0,62 & 0,72 & 1,12 & 18,35 & $\hat{Y}=0,0246 x+0,502$ & 0,80 \\
\hline EANDT (kg NDT/h) & 1,14 & 1,13 & 1,32 & 1,75 & 18,27 & $\hat{Y}=1,33$ & - \\
\hline \multicolumn{8}{|c|}{ Eficiência de ruminação } \\
\hline ERMS (kg MS/h) & 1,15 & 1,64 & 1,54 & 2,11 & 15,01 & $\hat{\mathrm{Y}}=1,61$ & - \\
\hline ERFDN (kg FDN/h) & 0,77 & 0,80 & 0,73 & 0,82 & 14,01 & $\hat{Y}=0,78$ & - \\
\hline ERCNF (kg CNF/h) & 0,39 & 0,46 & 0,44 & 0,75 & 16,39 & $\begin{array}{c}\hat{Y}=0,001 x^{2}- \\
0,011 x+0,411\end{array}$ & 0,89 \\
\hline ERNDT (kg NDT/h) & 0,77 & 0,84 & 0,81 & 1,18 & 15,41 & $\begin{array}{c}\hat{\mathrm{Y}}=0,001 \mathrm{x}^{2}- \\
0,015 \mathrm{x}+0,795\end{array}$ & 0,88 \\
\hline
\end{tabular}

MS = matéria seca; FDN = fibra em detergente neutro; $\mathrm{CNF}=$ carboidratos não-fibrosos; NDT = nutrientes digestíveis totais; $\mathrm{CV}=$ coeficiente de variação (\%); $\mathrm{ER}=$ equação de regressão; $\mathrm{R}^{2}=$ coeficiente de determinação.
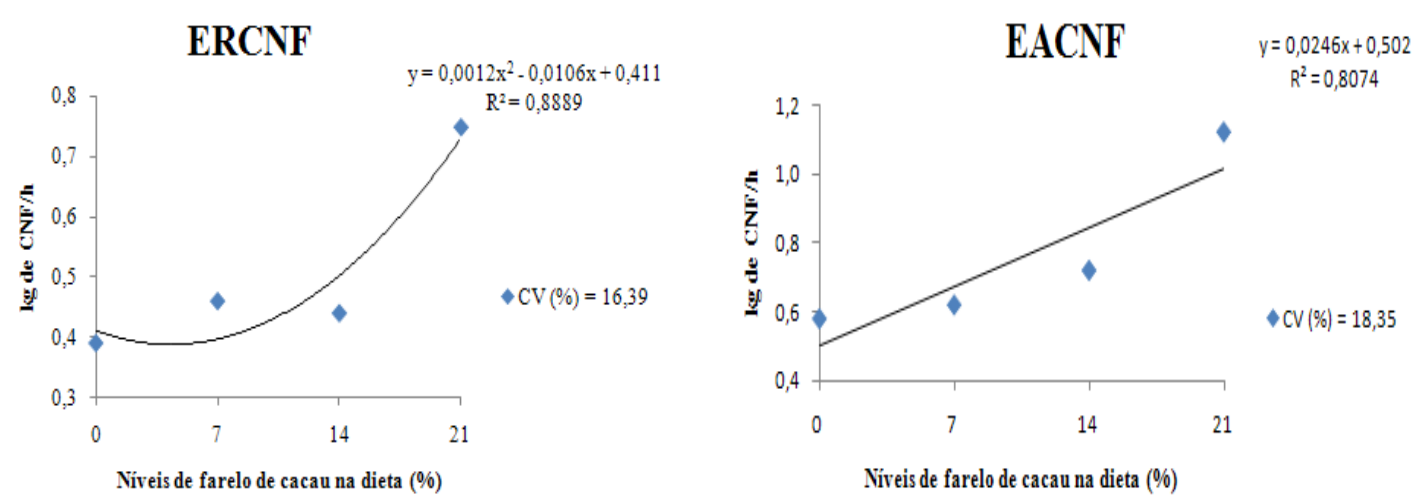

ERNDT

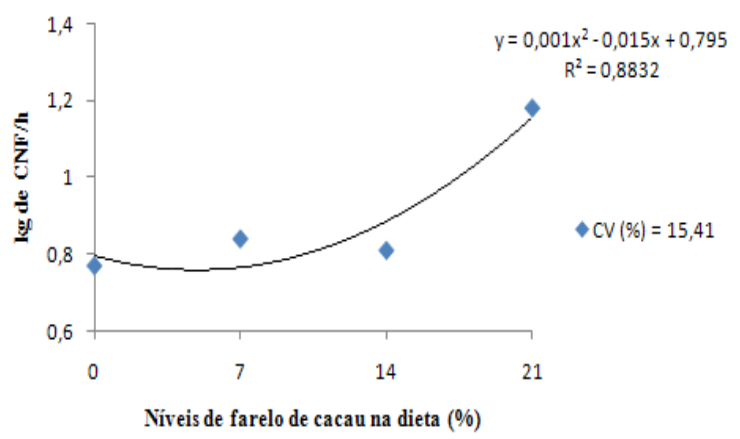

Figura 1. Eficiência de alimentação e ruminação dos carboidratos não-fibrosos (EACNF, ERCNF) e eficiência de ruminação de nutrientes digestíveis totais (ERNDT) 
Rev. Bras. Saúde Prod. Anim., Salvador, v.13, n.1, p.224-236 jan/mar, 2012 http://www.rbspa.ufba.br ISSN 15199940

As eficiências de ruminação apresentadas em $\mathrm{kg}$ de $\mathrm{MS} \mathrm{e}$ FDN, também não sofreram efeito da inclusão de farelo de cacau. Os resultados apresentam-se superiores aos encontrados por Silva et al. (2005) e Mendes Neto et al. (2007), como citado anteriormente. As análises de regressão apresentam efeito quadrático dos tratamentos para a eficiência de alimentação de carboidratos não fibrosos (ERCNF) e eficiência de ruminação de nutrientes digestíveis totais (ERNDT). Silva et al. (2005) observaram valores inferiores de ERCNF. Ao se comparar os valores de eficiência de ruminação do atual estudo com os dos demais, que já foram relatados, observa-se que os do presente estudo foram superiores. Esse fato corrobora Dulphy et al. (1980), quando afirmaram que a elevação de concentrado na dieta eleva, também, a eficiência de ruminação, uma vez que parte do concentrado é regurgitado, concomitantemente com o volumoso, para ser ruminado. Tal constatação é ainda mais ressaltada quando se observa a relação volumoso:concentrado de $53,3: 46,7$ no tratamento com $21 \%$ de farelo de cacau, valor este considerável, quando as dietas são fornecidas para novilhas leiteiras em crescimento.

A inclusão de até $21 \%$ de farelo de cacau na dieta total não promoveu alterações no comportamento ingestivo de novilhas leiteiras, o que o torna um promissor resíduo a ser introduzido nos programas de alimentação animal.

\section{AGRADECIMENTOS}

Ao Conselho Nacional de Desenvolvimento Científico e Tecnológico, pela concessão de bolsa a Alyson Andrade Pinheiro e pela ajuda financeira ao projeto.

\section{REFERENCIAS}

BÜRGER, P.J.; PEREIRA, J.C.;

QUEIROZ, A.C.; SILVA, J.F.C. da; VALADARES FILHO, S.C.; CECON, P.R.; CASALI, A.D.P. Comportamento ingestivo em bezerros holandeses alimentados com dietas contendo diferentes níveis de concentrado.

Revista Brasileira de Zootecnia, v.29, n.1, p.236-242, 2000.

CAPELLE, E.R.; VALADARES

FILHO, S.C.; SILVA, J.F.C.; CECON, P.R. Estimativas do valor energético a partir de características químicas e bromatológicas dos alimentos. Revista Brasileira de Zootecnia, v.30, n.6, p.1837-1856, 2001.

CARVALHO, G.G.P.; PIRES, A.J.V.; SILVA, F.F.; VELOSO, C.M.; SILVA, R.R.; SILVA, H.G.O.; BONOMO, P.; MENDONÇA, S.S. Comportamento ingestivo de cabras leiteiras alimentadas com farelo de cacau ou torta de dendê.

Pesquisa Agropecuária Brasileira, v.39, n.9, p.919-925, 2004.

CARVALHO, G.G.P.; PIRES, A.J.V.; VELOSO, C.M.; SILVA, F.F.; SILVA, R.R. Desempenho e digestibilidade de ovinos alimentados com farelo de cacau (Theobroma cacao L.) em diferentes níveis de substituição. Ciência Animal Brasileira, v.7, n.2, p.115-122, 2006.

CARVALHO, G.G.P.; PIRES, A.J.V.; SILVA, H.G.O; VELOSO, C.M.; SILVA, R.R. Aspectos metodológicos do comportamento ingestivo de cabras lactantes alimentadas com farelo de cacau e torta de dendê. Revista

Brasileira de Zootecnia, v.36, n.1, p.103-110, 2007. 
Rev. Bras. Saúde Prod. Anim., Salvador, v.13, n.1, p.224-236 jan/mar, 2012 http://www.rbspa.ufba.br ISSN 15199940

CARVALHO, G.G.P.; PIRES, A.J.V.;

SILVA, R.R.; RIBEIRO, L.S.O.; CHAGAS, D.M.T. Comportamento ingestivo de ovinos Santa Inês alimentados com dietas contendo farelo de cacau. Revista Brasileira de

Zootecnia, v.37, n.4, p.660-665, 2008.

COMPÊNDIO BRASILEIRO DE ALIMENTAÇÃO ANIMAL. Brasília: M.A., SINAA, ANFAR, CBNA, 2002. p.146-150.

DULPHY, J.P.; REMOND, B.; THERIEZ, M. Ingestive behaviour and related activities in ruminants. In: RUCKEBUSH, Y., THIVEND, P. (Eds.). Digestive physiology and metabolism. Lancaster: MTP, 1980. p.103-122.

GARY, L.A., SHERRITT, G.W., HALE, E.B. Behavior of Charolais cattle on pasture. Journal of Animal Science, v.30, p.303-306, 1970.

MENDES NETO, J.; CAMPOS, J.M.S.; VALADARES FILHO, S.C.; LANA, R.P.; QUEIROZ, A.C.de.; EUCLYDES, R.F. Comportamento ingestivo de novilhas leiteiras alimentadas com polpa cítrica em substituição ao feno de capimtifton 85. Revista Brasileira de

Zootecnia, v.36, n.3, p.618-625, 2007.

MENDONÇA, S.S.; CAMPOS, J.M. VALADARES FILHO, S.C.; VALADARES, R.F.D.; SOARES, C.A.; LANA, R.P.; QUEIROZ, A.C.de.; ASSIS, A.J.; PEREIRA, M.L.A. Comportamento ingestivo de vacas leiteiras alimentadas com dietas à base de cana-de-açúcar ou silagem de milho.

Revista Brasileira de Zootecnia, v.33, p.723-728, 2004.

MERTENS. D.R. Predicting intake and digestibility using mathematical models of ruminal function. Journal of Animal Science, v.64, n.7, p.1548-1558, 1987.
NATIONAL RESEARCH COUNCIL NRC. Nutrient requirements of dairy cattle. 7.ed. Washington, D.C.: National Academic Press, 2001. 381p.

PEREIRA, E.S.; MIZUBUTI, I.Y.; RIBEIRO, E.L.A.; VILLARROEL, A.B.S.; PIMENTEL, P.G. Consumo, digestibilidade aparente dos nutrientes e comportamento ingestivo de bovinos da raça Holandesa alimentados com dietas contendo feno de capim-tifton $85 \mathrm{com}$ diversos tamanhos de partícula. Revista Brasileira de Zootecnia, v.38, n.1, p.190-195, 2009.

PEREIRA, J.C.; CUNHA, D.N.F.V.; CECON, P.R.; FARIA, E.S.

Comportamento ingestivo e taxa de passagem de partículas em novilhas leiteiras de diferentes grupos genéticos submetidas a dietas com diferentes níveis de fibra. Revista Brasileira de Zootecnia, v.36, n.6, p.2134-2142, 2007.

PIRES, A.J.V.; VIEIRA, V.F.; SILVA, F.F.; VELOSO, C.M.; SOUZA, A.L.; OLIVEIRA, T.N.; SANTOS, C.L.; CARVALHO, G.G.P. Níveis de farelo de cacau (Theobroma cacao) na alimentação de bovinos. Revista Eletrônica de Veterinária, v.6, n.2, p.1-10, 2005.

PIRES, A.J.V.; CARVALHO JÚNIOR, J.N.; SILVA, F.F.; SOUZA, A.L.; OLIVEIRA, T.N.; SANTOS, C.L.; CARVALHO, G.G.P.; BERNARDINO, F.S. Farelo de cacau (Theobroma cacao) na alimentação de ovinos. Revista Ceres, v.26, n.286, p.33-46, 2004.

SILVA, D.J.; QUEIRÓZ, A.C. Análise de alimentos: métodos químicos e biológicos. 3.ed. Viçosa: Universidade Federal de Viçosa, 2002. 235p. 
Rev. Bras. Saúde Prod. Anim., Salvador, v.13, n.1, p.224-236 jan/mar, 2012 http://www.rbspa.ufba.br ISSN 15199940

SILVA, R.R.; SILVA, F.F.;

CARVALHO, G.G.P.; FRANCO, I.L.;

VELOSO, C.M.; CHAVES, M.A.;

BONOMO, P.; PRADO, I.N.;

ALMEIDA, V.S. Comportamento ingestivo de novilhas mestiças de holandês x zebu confinadas. Archivos de Zootecnia, v.54, n.205, p.75-85, 2005.

SNIFFEN, C.J.; O'CONNOR, J.D.; VAN SOEST, P.J.; RUSSEL, J.B.; FOX, D.G. A net carbohydrate and protein system for evaluating cattle diets: II. Carbohydrate and protein availability. Journal of Animal

Science, v.70, n.12, p.3562-3577, 1992.
UNIVERSIDADE FEDERAL DE

VIÇOSA - UFV. Sistema para análise estatística e genética- SAEG. Versão

8.0. Viçosa, MG: Fundação Arthur Bernardes, 2001. 150p.

VAN SOEST, P.J. Nutritional ecology of the ruminant. 2 ed. Ithaca: Cornell University Press, 1994, 476p.

ZANINE, A.M.; VIEIRA, B.R.; FERREIRA, D.J.; VIEIRA, A.J.M.; LANA, R.P.; CECON, P.R.

Comportamento ingestivo de vacas Girolandas em pastejo de Brachiaria brizantha e Coast-cross. Revista Brasileira de Saúde e Produção Animal, v.10, n.1, p.85-95, 2009.

Data de recebimento: $11 / 11 / 2010$ Data de aprovação: 02/12/2011 